\title{
SMART TOURISM INFORMATION AND MANAGEMENT (SARITEM) KOTA PALEMBANG BERBASIS ANDROID
}

\author{
Hafiz Irsyad $^{1}$, Akhsani Taqwiym ${ }^{2}$, Novan Wijaya ${ }^{3}$ \\ ${ }^{1}$ Teknik Informatika, STMIK GI MDP, ${ }^{2}$ Komputerisasi Akutansi, STMIK GI MDP, \\ ${ }^{3}$ Manajemen Informatika, AMIK Multi Data Palembang, \\ Jl. Rajawali No.14, Palembang 30113 Indonesia \\ E-mail: ${ }^{1}$ hafizirsyad@mdp.ac.id, ${ }^{2} a k h s a n i . t a q w i y m @ m d p . a c . i d,{ }^{3}$ novan.wijaya@mdp.ac.id
}

\begin{abstract}
Abstrak
Pariwisata adalah fenomena sosial, budaya dan ekonomi yang memerlukan pergerakan orang ke negara-negara atau tempat-tempat di luar lingkungan mereka untuk pribadi atau bisnis/tujuan-tujuan profesional. Pariwisata cerdas (Smart Tourism) dapat dilihat sebagai perkembangan logis dari pariwisata tradisional kearah e-pariwisata di bahwa dasar untuk inovasi dan orientasi teknologi industri dan wisatawan menjadi fokus dengan adopsi luas informasi dan komunikasi teknologi (ICT) di bidang pariwisata. Tujuan informasi wisata pintar (smart tourism informasi) sebagai tujuan wisata yang inovatif, dibangun di atas infrastruktur teknologi state-of-the-art menjamin pembangunan berkelanjutan dari kawasan wisata, diakses oleh semua orang, yang memfasilitasi interaksi pengunjung dengan dan integrasi ke dalam lingkungan nya, meningkatkan kualitas pengalaman di tempat tujuan, dan meningkatkan kualitas hidup penduduk. Dengan berkembang teknologi smartphone, memungkinkan untuk seseorang dalam mengakses sebuah informasi dimanapun dan kapanpun. Kota Palembang merupakan kota yang sering melakukan kegiatan wisata atau event-event yang bersifat nasional maupun internasional (ASIAN GAMES 2018). Dengan adanya wisata atau event diharapkan menambah devisa bagi kota Palembang. Maka dibutuhkan sebuah aplikasi yang bisa membantu para wisatawan baik dari dalam dan luar negeri dalam mengkases informasi mengenai kota Palembang.
\end{abstract}

Kata Kunci - Smart Tourism, ASIAN GAMES, Smartphone

\begin{abstract}
Tourism is a social, cultural and economic phenomenon that requires the movement of people to countries or places outside of their environment for personal or business / professional purposes. Smart Tourism can be seen as a logical development of traditional tourism towards etourism in that the basis for innovation and technological orientation of industry and tourists is the focus of the widespread adoption of information and communication technology (ICT) in tourism. The purpose of smart tourist information as an innovative tourism destination, built on state-of-the-art technology infrastructure ensures sustainable development of the tourist area, accessible to everyone, which facilitates visitor interaction with and integration into its environment, improve the quality of experience at the destination, and improve the quality of life of the population. With the growing technology of smartphones, allowing for a person in accessing any information wherever and whenever. Palembang city is a city that often do tourism activities or events that are national or international (ASIAN GAMES 2018). With the tourism or event is expected to increase foreign exchange for the city of Palembang. So needed an application that can help the tourists both from within and outside the country in assessing information about the city of Palembang.
\end{abstract}

Keywords: Smart Tourism, ASIAN GAMES 2018, Smartphone 


\section{PENDAHULUAN}

Sektor pariwisata merupakan salah satu penyumbang devisa negara dari banyak sektor. Bahkan, diperkirakan pada 2019 sudah mengalahkan pemasukan devisa dari industri kepala sawit (Crude Palm Oil). Menurut data yang berhasil finance.detik.com menyimpulkan devisa dari sektor pariwisata pada 2016 sebesar US\$13.568 miliar berada di posisi kedua setelah Crude Palm Oil (CPO) US\$12.225 miliar atau berada di posisi keempat di bawah migas US\$18.574 miliar, CPO US $\$ 16.427$ miliar, dan batu bara US\$14.717 miliar [1]. Kota Palembang khususnya mempunyai cara tersendiri untuk mencapai target yang telah ditetapkan pemerintah seperti yang telah dilakukan diantaranya penambahan jumlah negara yang bebas visa ke indonesia, menaikkan anggaran untuk promosi pariwisata, menjadikan pembangunan sebagai daya tarik wisata meliputi wisata alam, budaya dan kerajinan seni buatan manusia, dan melakukan eventevent baik nasional maupun internasional [2]. Untuk event internasional dalam waktu dekat yang akan diselengarakan di kota palembang sendiri yaitu pelaksanaan ASIAN GAMES 2018. Event ini diyakinkan mendatangkan banyak wisatawan ke kota palembang. Untuk saat ini, masih banyak wisatawan yang mencari informasi suatu daerah dengan menggunakan website tertentu, sehingga dibutuhkan sebuah aplikasi yang berbasis android agar memudahkan wisatawan dalam mencari informasi yang diinginkan [3].

Kota Palembang yang telah banyak mengadakan event-event tetapi belum mempunyai sebuah teknologi yang mampu membantu para wisatawan dalam mencari informasi mengenai kota Palembang ketika berada di kota Palembang. Strategi yang dapat digunakan untuk mengelolah informasi atau industri pariwisata yaitu informasi wisata cerdas (Smart Tourism Information) berbasis android, mengingat dengan kemajuan teknologi yang begitu pesat khususnya dalam pengembangan smartphone [2]. Smart tourism infromation merupakan campuran produk dan jasa wisata [4]. Ekspetasi wisatawan tentang transportasi, akomodasi, restoran, dukungan aktifitas dan event menjadi sumber masukan untuk memberikan layanan yang berfokus pada layanan personal cerdas untuk meningkatkan wisata [5].

Para wisatawan maupun atlit yang telah datang ke Palembang dalam rangka mengikut event bisa dengan mudah mencari informasi mengenai kota Palembang dengan menggunakan SARITEM. Perangkat lunak berbasis android yang akan dikembangkan bersifat real-time sehingga mempermudah para wisatawan yang akan mencari informasi. Dengan mudahnya mencari informasi mengenai kota Palembang diharapkan mampu menaikkan devisa khususnya untuk kota Palembang.

\section{METODE PENELITIAN}

Smart Tourism Information and Management (SARITEM) membutuhkan interkoneksi yang dinamis diantara kepentingan melalui platform teknologi sehingga bisa bertukar informasi secara real-time yang berkaitan degan event atau informasi pariwisata. Platform terintegrasi memiliki beberapa titik sentuh yang bisa diakses melalui berbagai perangkat end-user yang akan mendukung penciptaan dan fasilitasi pengalaman pariwisata yang real-time dan meningkatkan efektivitas manajemen sumber daya pariwisata di seluruh sektor baik mikro ataupun sektor makro. Smart Tourism Information bertujuan untuk memanfaatkan teknologi guna meningkatkan informasi pariwisata dan meningkatkan efektivitas pengelolan sumber daya dalam memuaskan wisatawan yang bersifat berkelanjutan [6].

Metode yang digunakan dalam proses pengembangan perangkat lunak adalah prototype. 


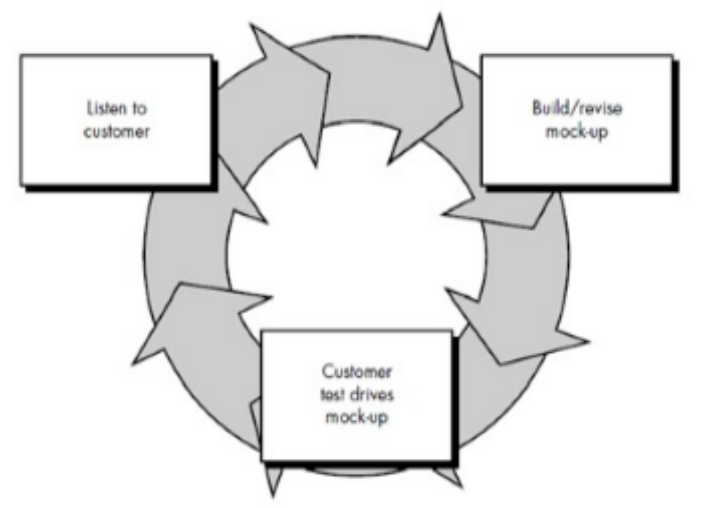

Gambar 1. Metode Prototype [7]

Adapun tahapan yang dilakukan berdasarkan metode prototype yaitu (1) menganalisis atribut-atribut produk pariwisata meliputi daya tarik dan atraksi, aksesbilitas, serta amenitas. Agar didapatkan kondisi produk pariwisata meliputi potensi, prasarana jalan dan transportasi, utilitas, akomodasi dan restoran, sarana dan fasilitas pendukung serta stakeholder yang berhubungan dengan produk pariwisata. (2) Menganalisis kebutuhan stakeholder pariwisata melalui pendekatan SARITEM yang berfokus pada pemerintah, wisatawan, masyarakat lokal, lingkungan hidup serta pelaku usaha dan industri wisata untuk mendapatkan kebutuhan data, informasi, proses bisnis dan aplikasi. Dan yang terkahir (3) membuat model pengembangan meliputi model proses bisnis, model data, daftar aplikasi dan arsitektur sistem informasi untuk SARITEM kota Palembang.

Alur penelitian yang dilakukan selama proses pengembangan perangkat lunak seperti pada Gambar 2.

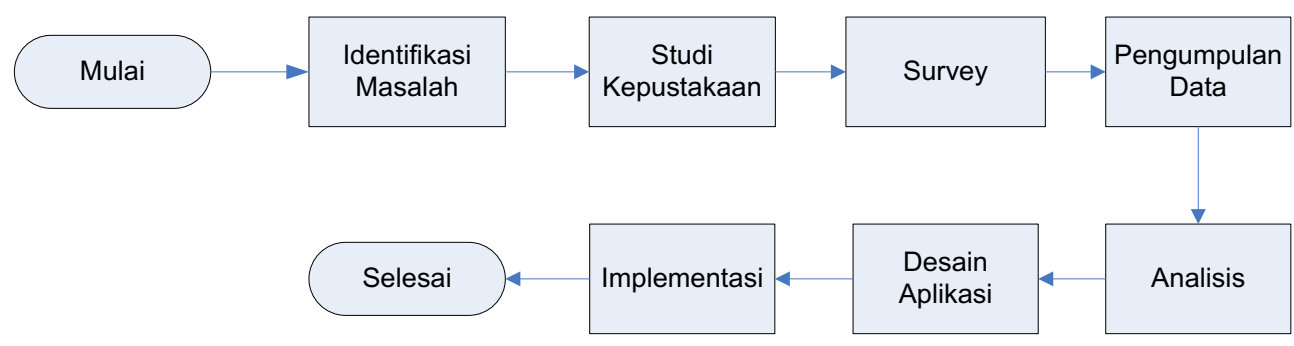

Gambar 2. Alur Pengembangan SARITEM

Adapun penjelasan dari alur penelitian pengembangan SARITEM dapat dilihat pada tabel 1.

Tabel 1 Tahapan Penelitian Pengembangan SARITEM

\begin{tabular}{|c|l|l|}
\hline No. & \multicolumn{1}{|c|}{ Tahapan } & \multicolumn{1}{|c|}{ Kegiatan } \\
\hline 1. & Identifikasi Masalah & $\begin{array}{l}\text { Mengidentifikasi masalah yang ada pada objek penelitian, agar } \\
\text { pengembangan lebih terarah. }\end{array}$ \\
\hline 2. & Studi Literatur & $\begin{array}{l}\text { Mengumpulkan literature yang berhubungan dengan masalah yang } \\
\text { diteliti. }\end{array}$ \\
\hline 3 & Survey & $\begin{array}{l}\text { Melakukan survey terhadap identifikasi yang ada di objek penelitian } \\
\text { untuk mendapat data-data pendukung }\end{array}$ \\
\hline 4 & Pengumpulan Data & $\begin{array}{l}\text { Mengumpulkan data-data hasil untuk dapat dilakukan analisis dan } \\
\text { perancangan }\end{array}$ \\
\hline 5 & Analisis dan Desain & $\begin{array}{l}\text { Menganalisis kebutuhan data dan informasi untuk pariwisata kota } \\
\text { Palembang }\end{array}$ \\
\hline 6 & Implementasi & $\begin{array}{l}\text { Mengimplementasikan hasil analisis dalam bentuk arsitektur sistem } \\
\text { informasi }\end{array}$ \\
\hline
\end{tabular}


Data yang didapatkan dari proses wawancara dan observasi. Wawancara dilakukan untuk mendapatkan alur proses, kebutuhan data dan informasi mengenai pariwisata atau event-event yang akan diselenggarakan di kota Palembang. Sedangkan observasi dilakukan untuk mengamati lokasi dan kunjungan objek wisata. Observasi merupakan salah satu kegiatan empiris yang mendasarkan fakta-fakta lapangan maupun teks, melalui pengalaman panca indra tanpa menggunakan manipulasi apapun [8].

\section{HASIL DAN PEMBAHASAN}

Hasil analisis yang telah dilakukan untuk menentukan kebutuhan pengembangan SARITEM kota Palembang didapatkan kebutuhan data dan informasi model proses, model data dan arsitektur sistem berdasarkan kebutuhan stakeholder. Dengan menggunakan javascript diharapkan aplikasi yang dikembangkan mampu digunakan di semua platform sehingga para wisatawan tidak mengalami kesulitan. Aplikasi yang dikembangkan juga bersifat real time sehingga dengan mengisikan pada menu saran dan kritik yang terhubung ke administrator dalam hal ini pemerintah, akan langsung menjawab keluhan para wisatawan. Pada tiap tampilan menu, akan dibuat sebuah penilaian kepada wisatwan setelah mereka menggunakan atau membuka menu tersebut. Penilaian inilah yang akan menjadikan acuan dalam tingkat kepuasaan wisatawan dalam menggunakan aplikasi SARITEM. Hasil analisis kebutuhan informasi dapat dilihat pada Tabel 2 .

Tabel 2. Kebutuhan SARITEM Kota Palembang

\begin{tabular}{|l|l|}
\hline Aktor & Kebutuhan Informasi \\
\hline Wisatawan & - Kritik dan Saran \\
& - Pencarian Informasi \\
& - Informasi Paket Wisata \\
& - Informasi Penginapan/Hotel \\
& - Informasi Transportasi \\
& - Informasi Fasilitas dan Sapras \\
& - Digitalisasi Destinasi \\
& - Informasi Kuliner \\
& - Event Pariwisata \\
\hline Pemerintah & - Destinasi Wisata \\
& - Fasilitas dan Sapras \\
& - Kebijakan dan Regulasi \\
& - Event Wisata \\
& Promosi Wisata \\
\hline
\end{tabular}

Berdasarkan kebutuhan informasi pada Tabel 2, dapat dilihat bahwa kebutuhan informasi yang harus disediakan untuk melakukan pelayanan terhadap pemerintah, wisatawan, pengrajin dan pelaku usaha pariwisata untuk memberikan layanan informasi yang optimal tentang destinasi wisata, maka dibuat model proses pengambangan SARITEM kota Palembang pada Gambar 3.

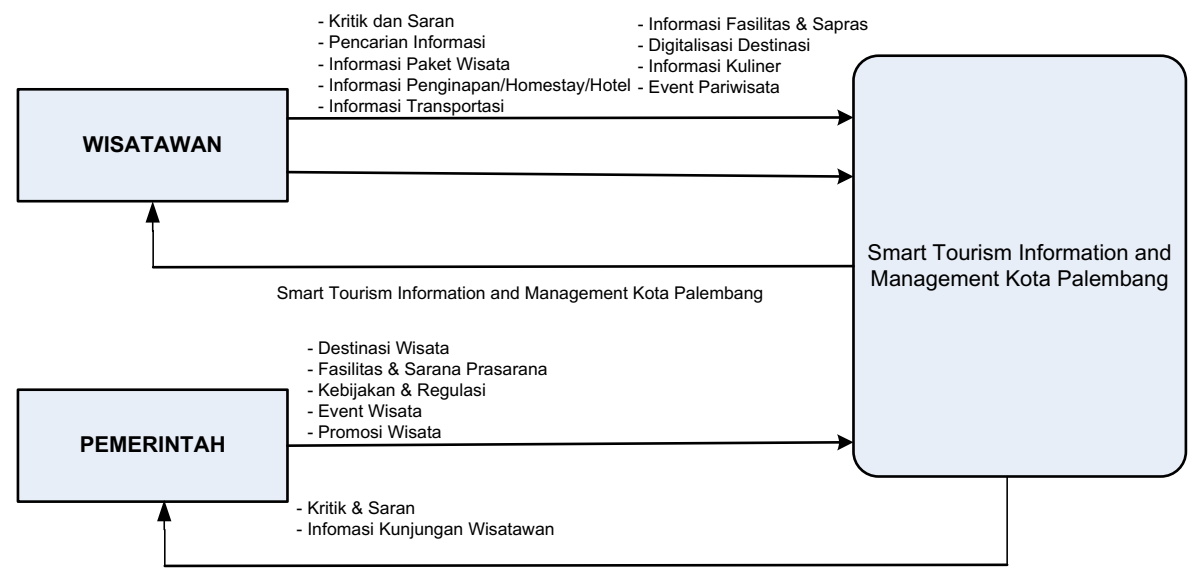

Gambar 3. Model Proses SARITEM Kota Palembang 
Model proses SARITEM kota Palembang pada Gambar 3, melibatkan wisatawan, pengrajin, pemerintah dan pelaku usaha pariwisata (hotel/penginapan, biro perjalanan wisata, transportasi, restoran, tour guide) yang di integrasikan dalam satuan kesatuan sistem untuk memberikan pelayanan yang optimal kepada wisatawan. Informasi yang diberikan bersifat realtime karena data di update langsung dari pemerintah, pelaku usaha pariwisata, pengrajin dan wisatwan. Berdasarkan kritik dan saran yang disediakan, pemerintah dapat terus meningkatkan fasilitas, sarana dan prasarana untuk menunjang destinasi wisata sehingga dapat memberikan kemudahan dan kenyaman pada wisatawan. Pelaku usaha wisata dapat terus meningkatkan layanan produk dan jasa yang dimiliki. Pengrajin dapat terus berinovasi terhadap produk yang dibuat. Tentunya hal ini dapat mengoptimal pelayanan pada destinasi wisata kota Palembang. Berdasarkan model proses pada Gambar 3, dapat dibuat tabel kebutuhan entitas data untuk SARITEM kota Palembang pada Tabel 3.

Tabel 3. Entitas Data SARITEM

\begin{tabular}{|l|l|}
\hline Proses Bisnis & Entitas Data \\
\hline Promosi & - Permcarian Informasi \\
Pariwisata & - Data Objek Wisata \\
& - Data Fasilitas, Sarana dan Prasarana \\
& - Data Event Wisata \\
& - Data Sarana Transportasi \\
& - Data hotel penginapan \\
& - Data barang Jasa \\
& - Data Paket Wisata \\
& - Data Saran dan Kritik \\
\hline Layanan Wisata & - Data Kunjungan Wisatawan \\
& - Data Pemesanan Paket Wisata \\
& - Data Pemesanan Transportasi \\
& - Data Pemesanan Hotel Penginapan \\
& - Data Penggunaan Jasa Pariwisata \\
& - Data Saran dan Kritik \\
& - Data regulasi dan Kebijakan \\
\hline
\end{tabular}

Entitas data pada Tabel 3, digunakan untuk menampung data proses promosi dan layanan wisata kota Palembang dan digunakan sebagai sumber untuk memberikan informasi yang realtime kepada aktor yang ada dalam SARITEM wisata kota Palembang. Berdasarkan entitas yang telah didapatkan dibuat model data untuk pengembangan SARITEM kota Palembang pada Gambar 4.

Entiti diagram pada Gambar 3, dibuat berdasarkan tabel entiti data pada tabel 2, berfokus pada wisatawan, pengrajin, pelaku usaha pariwisata dan pemerintah. Data objek wisata didukung oleh data hotel, fasilitas, sarana dan prasarana, event wisata, transportasi, paket wisata dan usaha wisata, sehingga sumber data untuk informasi destinasi wisata dapat diberikan kepada wisatawan dengan lengkap dan real-time. Data wisatawan didukung oleh data kunjungan wisata, data pemesanan hotel/penginapan, pemesanan paket wisata, data pemesanan transportasi, data saran dan kritik, sehingga mempermudah mendapatkan informasi yang berhubungan wisatawan, berupa saran dan kritik terhadap peningkatan layanan wisata, dan informasi kunjungan wisatawan. 


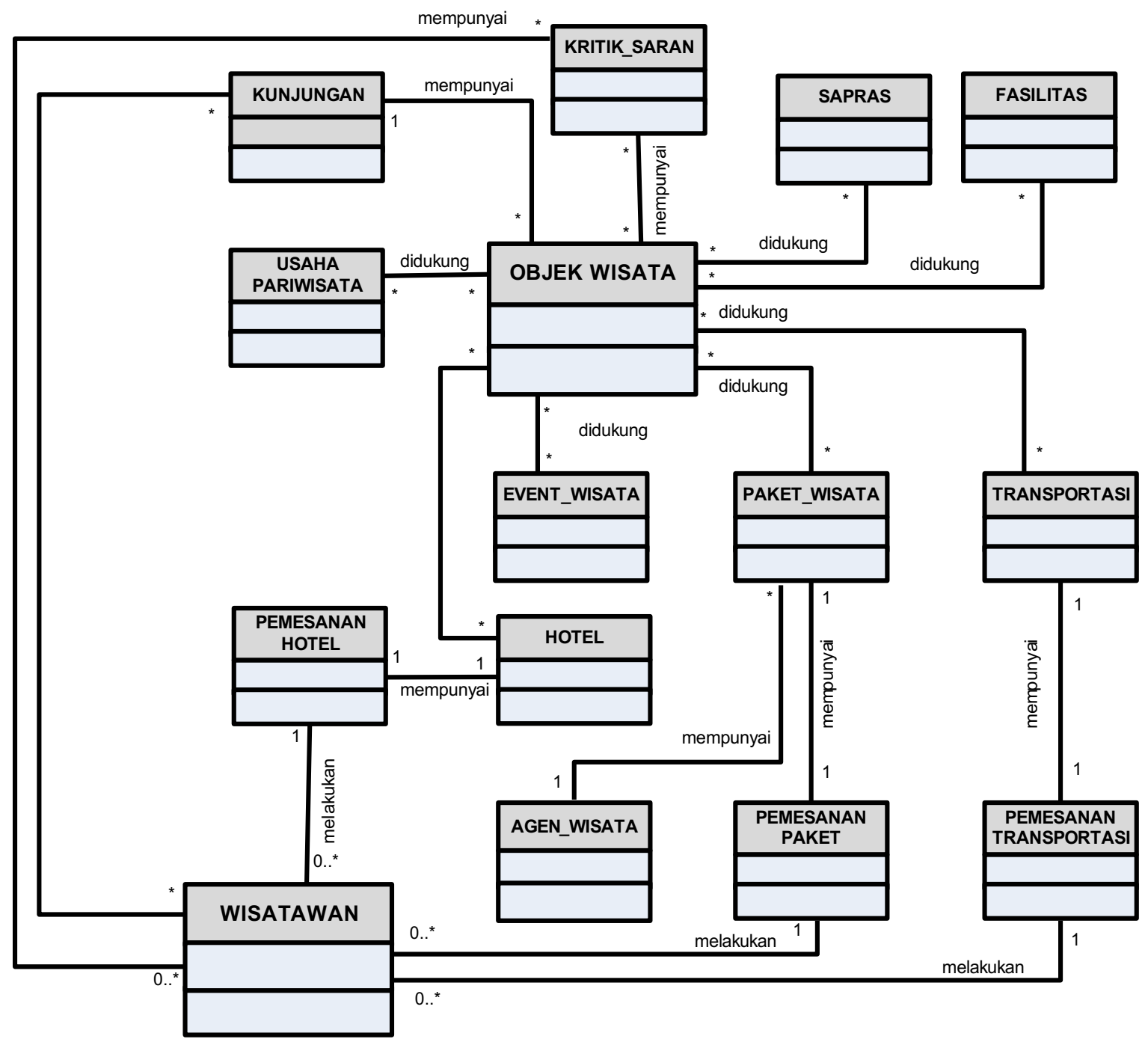

Gambar 4. Entity Relationship Diagram

Berdasarkan gambar 4, maka dapat ditentukan struktur tabel penyimpanan data. Tabel 4 merupakan Struktur Tabel Objek Wisata yang digunakan untuk menyimpan data yang berhubunga dengan objek wisata sehingga data objek wisata bisa diperbaharui pada saat terjadi perubahan.

Tabel 4. Struktur Tabel Objek Wisata

\begin{tabular}{|c|l|l|l|}
\hline No & Nama Field & Tipe Data & Keterangan \\
\hline 1 & Id_ObjekWisata & Text & ID untuk masing-masing objek wisata \\
\hline 2 & Nama_ObjekWisata & Text & Nama Objek Wisata \\
\hline 3 & Jenis_ObjekWisata & Text & Jenis Objek Wisata \\
\hline 4 & Keunggulan & Text & Keunggulan Objek Wisata \\
\hline 5 & Status_Kelolah & Text & Status Pengelolaan \\
\hline
\end{tabular}

Struktur Tabel 5 (Sapras) digunakan untuk menyimpan data sarana dan prasarana yang berhubungan dengan objek wisata sehingga dapat diketahui sarana dan prasarana pendukung objek wisata. 
Tabel 5. Struktur Tabel Sarana dan Prasarana

\begin{tabular}{|c|l|l|l|}
\hline No & Nama Field & Tipe Data & Keterangan \\
\hline 1 & Id_Sapras & Text & ID Sarana dan Prasarana \\
\hline 2 & Id_ObjekWisata & Text & ID untuk masing-masing objek wisata \\
\hline 3 & Jenis & Text & Jenis Sarana dan Prasarana \\
\hline 4 & Nama_Sapras & Text & Nama Sarana dan Prasarana \\
\hline 5 & Jumlah & Numeric & Jumlah Sapras \\
\hline 6 & Status_Sapras & Text & Status Sapras \\
\hline
\end{tabular}

Struktur Tabel Fasilitas digunakan untuk menyimpan data fasilitas yang berhubungan dengan objek wisata sehingga dapat diketahui fasilitas pendukung objek wisata, adapun struktur tabel fasilitas seperti pada Tabel 6 .

Tabel 6. Struktur Tabel Fasilitas

\begin{tabular}{|c|l|l|l|}
\hline No & Nama Field & Tipe Data & Keterangan \\
\hline 1 & Id_Fasilitas & Text & ID Fasilitas \\
\hline 2 & Id_ObjekWisata & Text & ID untuk masing-masing objek wisata \\
\hline 3 & Jenis & Text & Jenis Fasilitas \\
\hline 4 & Nama_Fasiltas & Text & Nama Fasilitas \\
\hline 5 & Jumlah & Numeric & Jumlah \\
\hline 6 & Status_Fasiltas & Text & Status Fasilitas \\
\hline
\end{tabular}

Struktur Tabel Transportasi digunakan untuk menyimpan data transportasi yang berhubungan dengan objek wisata sehingga dapat diketahui transportasi pendukung objek wisata, adapun struktur tabel transportasi seperti pada Tabel 7.

Tabel 7. Struktur Tabel Transportasi

\begin{tabular}{|c|l|l|l|}
\hline No & Nama Field & Tipe Data & Keterangan \\
\hline 1 & Id_Transportasi & Text & ID Transportasi \\
\hline 2 & Id_ObjekWisata & Text & ID untuk masing-masing objek wisata \\
\hline 3 & Jenis & Text & Jenis Transportasi \\
\hline 4 & Nama_Transportasi & Text & Nama Transportasi \\
\hline 5 & No_Telpon & Text & Nomor Telepon \\
\hline 6 & Contact & Text & Nama Contact \\
\hline
\end{tabular}

Struktur Tabel EventWisata digunakan untuk menyimpan data event wisata yang berhubungan dengan objek wisata sehingga dapat diketahui event wisata pendukung objek wisata, adapun struktur tabel EventWisata seperti pada Tabel 8.

Tabel 8. Struktur Tabel Event Wisata

\begin{tabular}{|c|l|l|l|}
\hline No & Nama Field & Tipe Data & Keterangan \\
\hline 1 & Id_EventWisata & Text & ID Event Wisata \\
\hline 2 & Id_ObjekWisata & Text & ID untuk masing-masing objek wisata \\
\hline 3 & Jenis_Event & Text & Jenis Event Wisata \\
\hline 4 & Nama_Event & Text & Nama Event Wisata \\
\hline 5 & Pelaksanaa & Text & Keterangan Pelaksanaan Event \\
\hline 6 & StatusEvent & Text & Status Event Wisata \\
\hline 7 & Deskripsi & Text & Deskripsi Event Wisata \\
\hline
\end{tabular}


Struktur Tabel hotel digunakan untuk menyimpan data hotel/penginapan yang berhubungan dengan objek wisata sehingga dapat diketahui hotel pendukung objek wisata, adapun struktur tabel usaha hotel seperti pada Tabel 9.

Tabel 9. Struktur Tabel Hotel

\begin{tabular}{|c|l|l|l|}
\hline No & Nama Field & Tipe Data & Keterangan \\
\hline 1 & Id_Hotel & Text & ID Hotel \\
\hline 2 & Id_ObjekWisata & Text & ID untuk masing-masing objek wisata \\
\hline 3 & Tipe Hotel & Text & Tipe/Kelas Hotel \\
\hline 4 & Nama_Hotel & Text & Nama Hotel \\
\hline 5 & Jumlah_Kamar & Numeric & Jumlah Kamar Hotel \\
\hline 6 & Alamat & Text & Alamat Usaha Wisata \\
\hline 7 & No_Telpon & Text & No Telepon \\
\hline 8 & Contact & Text & Nama Contact \\
\hline
\end{tabular}

Struktur Tabel KritikSaran digunakan untuk menyimpan data kritik dan saran terhadap pelayanan wisata yang berhubungan dengan objek wisata sehingga dapat diketahui saran dan kritik untuk memperbaiki pelayanan, adapun struktur tabel KritikSaran seperti pada Tabel 10.

Tabel 10. Struktur Tabel Kritik dan Saran

\begin{tabular}{|c|l|l|l|}
\hline No & Nama Field & Tipe Data & Keterangan \\
\hline 1 & Id_Hotel & Text & ID Hotel \\
\hline 2 & Id_ObjekWisata & Text & ID untuk masing-masing objek wisata \\
\hline 3 & Tipe Hotel & Text & Tipe/Kelas Hotel \\
\hline 4 & Nama_Hotel & Text & Nama Hotel \\
\hline 5 & Jumlah_Kamar & Numeric & Jumlah Kamar Hotel \\
\hline 6 & Alamat & Text & Alamat Usaha Wisata \\
\hline 7 & No_Telpon & Text & No Telepon \\
\hline 8 & Contact & Text & Nama Contact \\
\hline
\end{tabular}

Tabel 2 menggambarkan kewenangan masing-masing pemakai SARITEM kota Palembang untuk mengakses aplikasi, yang disesuaikan dengan tingkat kebutuhan terhadap pengolahan dan akses informasi, sehingga dapat meningkat keamanan terhadap data yang ada. Tahap selanjutnya dapat digambarkan arsitektur sistem informasi untuk SARITEM yang menggambarkan satu kesatuan data dan informasi. Adapun Arsitektur yang diusulkan pada Gambar 5.

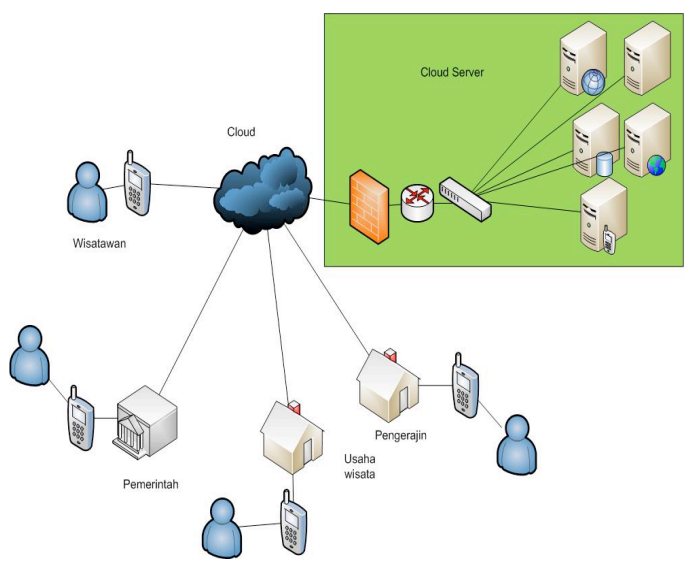

Gambar 5. Arsitektur Sistem Informasi 
Cloud Computing merupakan sebuah model penyediaan layanan komputasi di mana layanan sumber daya komputasi disediakan secara dinamis, scalable dan bersifat virtual melalui jaringan komputer atau internet [9]. Arsitektur informasi yang diusulkan menggunakan Cloud Computing sebagai server, memudahkan akses terhadap informasi yang berhubungan dengan destinasi wisata kota Palembang yang dapat diakses melalui perangkat mobile. Sementara dalam melakukan pengujian menggunakan metode black box testing. Dimana pengujian black box adalah pengujian yang dilakukan dengan cara menguji aplikasi dengan memasukkan data ke dalam form yang telah disediakan [10]. Pembuatan interface untuk SARITEM dilakukan secara berurutan mulai dari perancangan sampai dengan membuat aplikasi yang diingikan. Pada tampilan awal SARITEM, wisatawan bisa memilih beberapa menu diantaranya : objek wisata yang ada di Palembang, fasilitas, event, transportasi, hotel, SARPRAS serta saran dan kritik (Gambar 6).

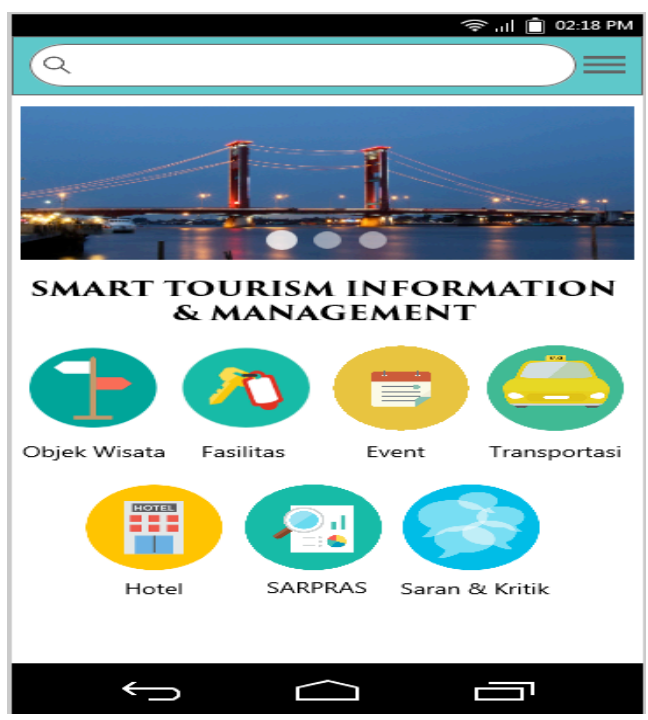

Gambar 6. Antarmuka Awal SARITEM

Jika wisatawan memilih menu objek wisata, akan mengeluarkan informasi berupa objek wisata apa saja yang bisa dikunjungi oleh para wisatawan (Gambar 7). Untuk objek wisata sendiri akan selalu diperbaharui jika ada sesuatu yang baru

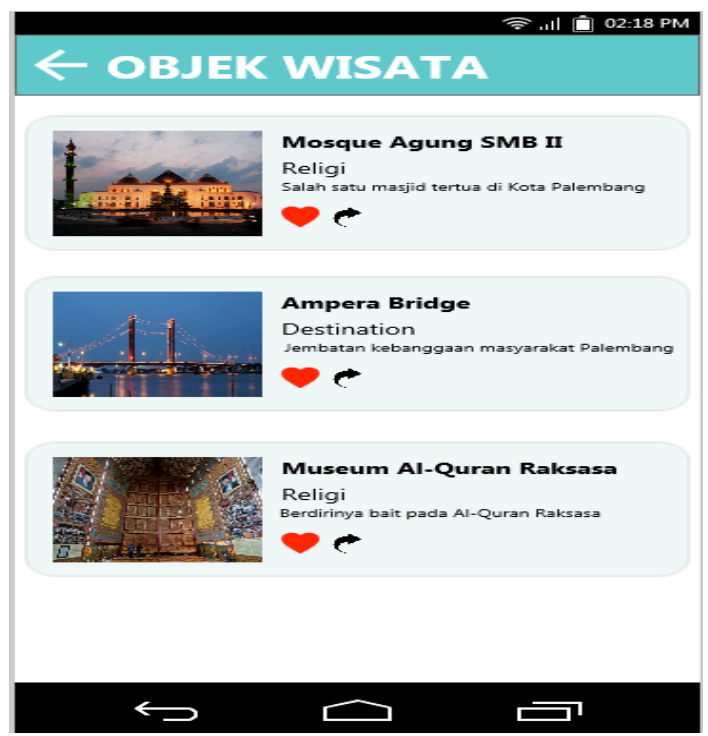

Gambar 7. Antarmuka Menu Objek Wisata 
Pada menu event, akan tersedia informasi mengenai event-event yang telah dilaksanakan, yang sedang dilaksanakan serta yang akan dilaksanakan di kota Palembang (Gambar 8). Sehingga para wisatawan diharapkan mengetahui ada event apa di kota Palembang.

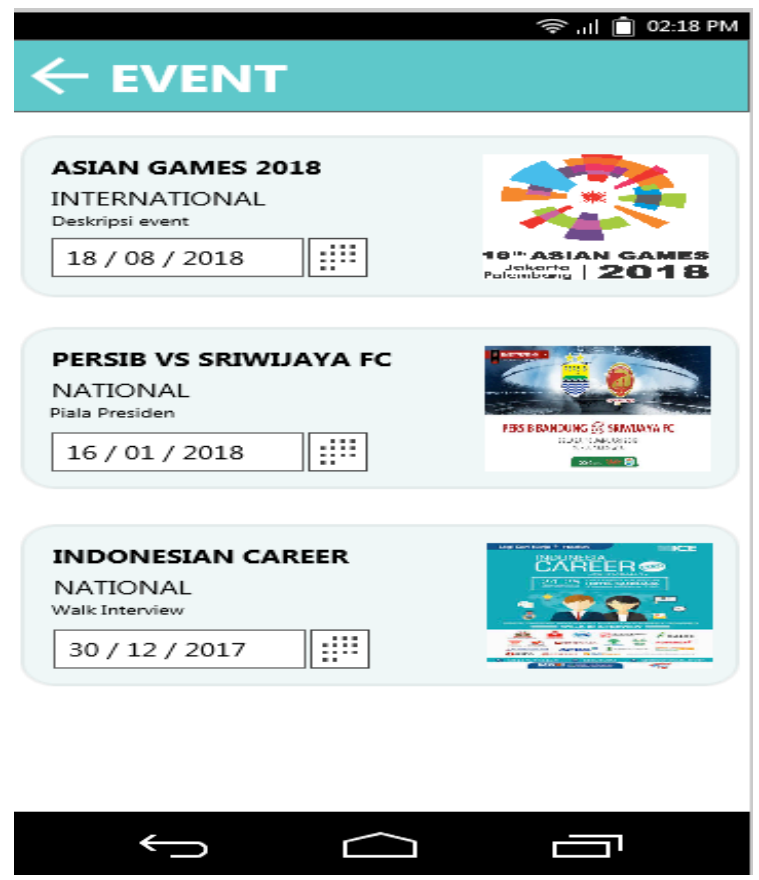

Gambar 8. Antarmuka Menu Event

Menu transportasi pada aplikasi SARITEM dapat digunakan untuk memesan transportasi selama berada di kota Palembang (Gambar 9). Menu ini akan selalu diperbaharui jika terjalin kerjasama dengan pihak transportasi lainnya sehingga para wisatawan merasakan kenyamaan ketika berada di kota Palembang.

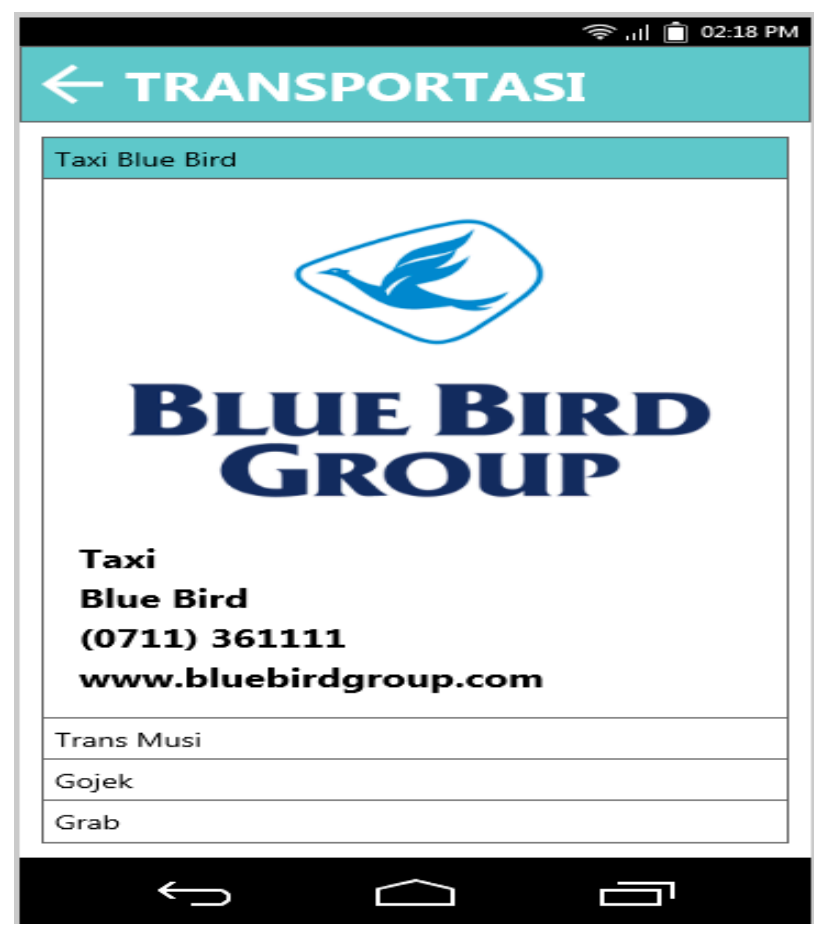

Gambar 9. Antarmuka Menu Transportasi 
Ketika memilih menu hotel pada aplikasi SARITEM, wisatawan dapat mengetahui hotel apa saja yang berada di kota Palembang (Gambar 10) dan dimana lokasi hotel tersebut sehingga para wisatawan dapat mencari lokasi hotel terdekat.

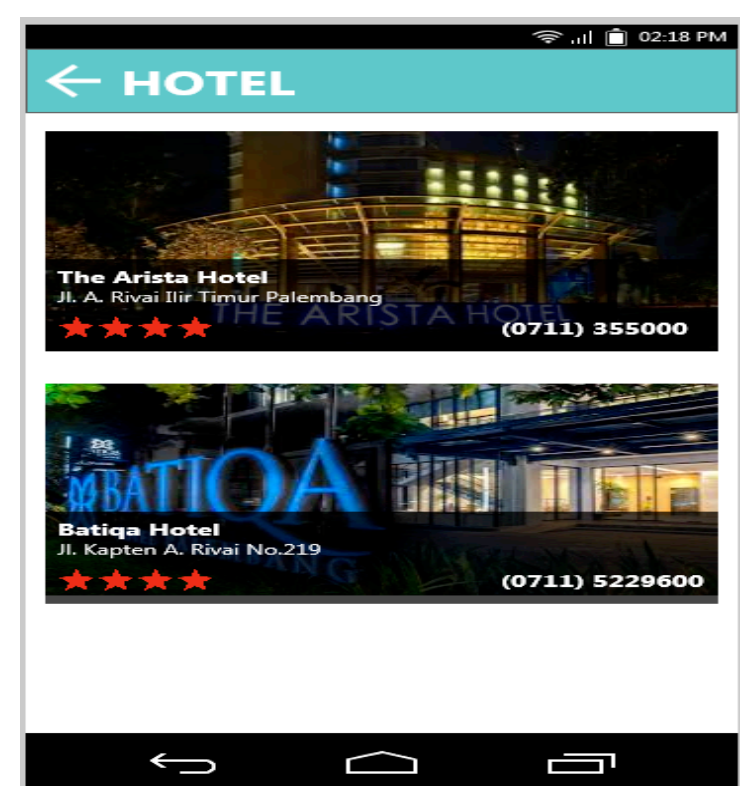

Gambar 10. Antarmuka Menu Hotel

Menu SARPRAS berisikan informasi mengenai tempat-tempat perbelanjaan atau tempat yang juga bisa dikunjungi para wisatawan (Gambar 11), sehingga ketika wisatwan memilih salah satu pilihan yang tersedia, maka akan diketahui lokasinya dan cara menuju sarana dan prasaran tersebut.

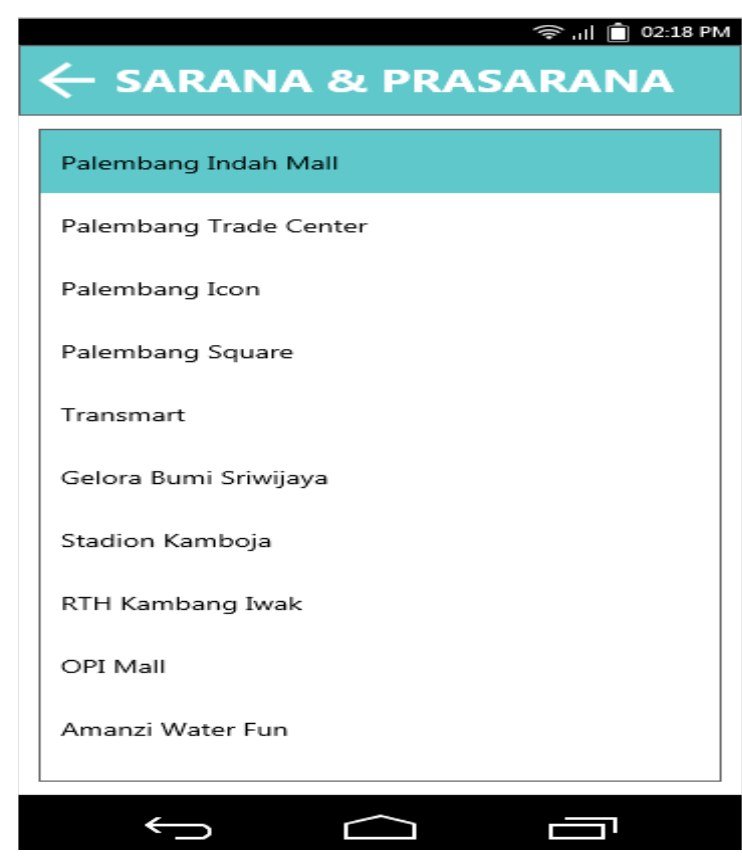

Gambar 11. Antarmuka Menu SaPras

Wisatawan dapat memberikan kritik dan saran kepada pengembang aplikasi yang terkoneksi dengan pemerintahan kota Palembang (gambar 12), sehingga akan selalui dilakuka perbaikan secara keseluruhan jika terdapat kesalahan. 


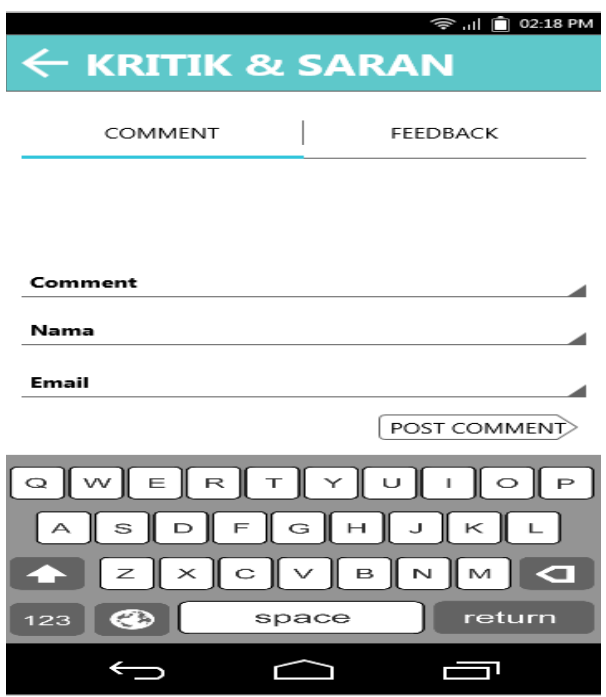

Gambar 12. Antarmuka Menu Kritik dan Saran

\section{KESIMPULAN}

Dalam beberapa tahun terakhir, kota Palembang banyak sekali mengadakan event baik bersifat nasional maupun internasional seperti PON dan SEA GAMES. Dengan adanya aplikasi SARITEM yang dikembangkan oleh pemerintahan kota Palembang diharapkan mampu membantu para wisatawan yang akan datang maupun yang telah berada di kota Palembang, baik yang maupun mengikuti event atau sekedar jalan-jalan di kota Palembang, sehingga tidak mengalami kesulitan dikarenakan semua informasi mengenai kota Palembang tersedia pada aplikasi tersebut. Untuk wisatwan yang telah melakukan proses instalasi aplikasi SARITEM, akan mendapatkan pemberitahuan terbaru jika terdapat event atau objek wisata terbaru di kota Palembang. Sehingga menjadi daya tarik tersendiri bagi wisatawan dalam datang ke kota Palembang dan menjadi tambahan devisa untuk kota Palembang..

\section{UCAPAN TERIMA KASIH}

Penulis mengucapkan terima kasih kepada STMIK Global Informatika MDP yang telah memfasilitasi penelitian ini.

\section{DAFTAR PUSTAKA}

[1] A. A. Chandra and D. Damarjati, "Tiga Tahun Jokowi-JK, Pariwisata Sumbang Devisa Terbesar Kedua," finance.detik.com, 2018. [Online]. Available:

https://finance.detik.com/berita-ekonomi-bisnis/3687715/tiga-tahun-jokowi-jkpariwisata-sumbang-devisa-terbesar-kedua. [Accessed: 15-Jan-2018].

[2] N. Wijaya, "PERANCANGAN APLIKASI PROMOSI SONGKET PALEMBANG BERBASIS ANDROID," JUSIM, vol. 2, no. 2, pp. 10-22, 2017.

[3] A. Taqwiym and N. WIjaya, "PERANCANGAN LOWONGAN KERJA ONLINE BERBASIS WEB PADA PT ANH,” J. Ilm. Inform., vol. 2, no. 1, pp. 112-116, 2017.

[4] K. Boes, D. Buhalis, and A. Inversini, "Conceptualising Smart Tourism Destination Dimensions," in Information and Communication Technologies in Tourism 2015, 2015, pp. 391-403. 
[5] D. Buhalis and A. Amaranggana, "Smart Tourism Destinations Enhancing Tourism Experience Through Personalisation of Services," in Information and Communication Technologies in Tourism 2015, 2015, pp. 377-389.

[6] D. Buhalis and A. Amaranggana, "Smart Tourism Destinations," in Information and Communication Technologies in Tourism 2014, 2013, pp. 553-564.

[7] M. Salahuddin and A. S. Rosa, Modul Pembelajaran Rekayasa Perangkat Lunak (Terstruktur dan Berorientasi Objek). Bandung: Modula, 2011.

[8] H. Hasanah, "TEKNIK-TEKNIK OBSERVASI (Sebuah Alternatif Metode Pengumpulan Data Kualitatif Ilmu-ilmu Sosial)," J. At-Taqaddum, vol. 8, no. 1, 2016.

[9] G. B. Putra, "Rancang Bangun Cloud Computing Di Laboratorium Komputer Teknik Elektro Universitas Bangka Belitung," J. Ecotipe, vol. 1, no. 1, pp. 14-22, 2014.

[10] R. Handrio, R. R. Isnanto, and E. D. Widianto, "Pembuatan Antarmuka Sistem Pemantau Ruangan Berbasis Web," J. Teknol. dan Sist. Komput., vol. 4, no. 4, pp. 497$501,2016$. 